\title{
Mixed Integer Nonlinear Optimization for ESP Lifted Oil Field and Improved Operation through Production Valve Choking
}

\author{
Roshan Sharma and Bjørn Glemmestad
}

\begin{abstract}
The demand for the total production of oil from an Electric Submersible Pump (ESP) lifted oil field may vary with time. It may not always be economically profitable to use all of the available oil wells for varying production rates. Depending on the amount of oil to be produced from the oil field, some of the oil wells may have to be shut down. The number of oil wells to be used should be properly selected. Not only the number of oil wells should be known, but which wells to use should also be exactly identified. The operating speed of the ESP and the production choke valve opening of each selected oil well should be optimally chosen so that the profit from the oil field is maximized by keeping the operational expenses at the minimum. The oil well scheduling problem is formulated as a Mixed Integer Nonlinear Programming (MINLP) problem. The cost of the electrical power consumed by the pumps, the operational cost of separation process and the income from the oil production are considered for the MINLP formulation. In the first part of the paper, the production choke valves are always fully opened and the number of wells and their respective pump speeds are calculated for varying total production flow rates. However, in the second half of the paper, it is shown that the operation of the oil field can be improved in terms of power consumption through production valve choking.
\end{abstract}

Index Terms-Mixed integer nonlinear programming, ESP lifted oil field, well scheduling, optimal operation, production valve choking.

\section{INTRODUCTION}

In an ESP lifted oil field, multiple oil wells are connected in parallel to a common gathering manifold. The oil produced from each of the wells is collected by the gathering manifold and then transported to the separator through the transportation lines (see Fig. 4). Each oil well is fitted with a multistage centrifugal pump. The main operational expense in the oil field is the total cost of power consumed by the pumps and the cost of operating the separator. The income is the production of crude oil from the field. The energy costs associated with the operation of the pumps in an ESP lifted oil field is of great significance when multiple oils wells are considered. The cost of operating the separator is less significant compared to the energy costs of the pumps.

The total amount of oil to be produced from the field may vary. For higher production rates from the oil field, all of the available oil wells may be used to meet the demand. On the

Manuscript received June 23, 2014; revised August 31, 2014.

The authors are with the Department of Electrical Engineering, Information Technology and Cybernetics, Telemark University College, Porsgrunn, Norway (e-mail: roshan.sharma@hit.no, bjorn.glemmestad@hit.no). contrary for lower production rates, some of the oil wells of the oil field can be shut down to meet the lower production demand. The lower the pump speed, the lower is the fluid flow rate through the well. However, running all of the available oil wells at lower pump speeds for fulfilling lower production demands might not be beneficial. The wells might be consuming more power than what is actually needed. Shutting down an oil well reduces the consumption of electric power as the ESP for the well is turned off. So, the balance between fulfilling the total production demand and using the oil wells economically should be maintained. As the production demand changes, the total number of oil wells to be operated has to be recalculated to meet this new demand. In addition, each of the chosen oil wells has to be operated in an optimal manner by satisfying all the operational constraints of the pump and the oil well. These operational constraints are described in the paper in Section III-A in detail. The speed of the pump and the production choke valve opening of each of the oil wells are the variables that can be manipulated to control the production of reservoir fluid from the oil field. The higher the speed of the pump, the higher the flow rate through the well but also the higher the consumption of electrical power. For example, operating three (out of four available) oil wells at higher speeds to meet a demand might consume more power than running all the four oil wells at lower speeds to meet the same demand. The oil wells have to be configured in such a way that the production demand is met and at the same time the operational expenses are at the minimum. The main interest is to find the number of oil wells to be used for a specified total fluid flow rate from the oil field. The optimal operating speed and the production choke valve opening of each selected oil well should also be calculated.

The well problem involves both the discrete variable (the number of oil wells to be used) and the continuous variables (the speed of the pumps and the choke valve openings). It is formulated as a MINLP problem. The objective of this paper is to find optimal operating conditions for the ESP lifted oil field. The paper does not focus on the development of algorithms for solving MINLP problems but rather deals with the implementation of Branch and Bound (BB) method for solving MINLP problems for ESP lifted oil fields. Well scheduling and parallel pumps configuration problem has been a topic of interest for various researchers. Mixed Integer Programming is applied to find the optimal locations of wells in an underground reservoir and the proper sequencing of flow rates from those wells so that the difference between the production demand and the actual flow is minimized [1], [2]. An Extended Cutting Plane (ECP) method combined with 
BB method is used for solving pump configurations as a MINLP problem in [3] with respect to minimizing the total cost including the investment and the running costs of the pumps. For a non convex pump configuration problem, global optimum solution is obtained by using binary separable programming [4]. The total energy consumed by the pumps in a water boosting system equipped with multiple variable speed pumps in parallel is minimized in [5] by controlling the number of running pumps and their corresponding speeds subject to potential changes of set points and operating conditions. Genetic algorithm is used for solving the pump scheduling in water supply in [6], [7]. A comparison between genetic algorithm and mathematical optimization for solving wells placement problem shows that the mathematical optimization provides better solutions and within less computational time [8].

The paper is organized as follows: In Section II, a brief description of the model of the oil field including the motor and pump models is given. Oil wells configuration problem is formulated as a MINLP problem and solved by considering the production choke valves to be always fully opened in Section III. In Section IV, it is shown that the production choke valves can also be controlled along with controlling the speed of the pump for profit maximization. The production choke valves can be slightly choked by keeping the pump speed constant for fulfilling a lower production demand and this significantly improves the operation of the ESP oil field. A simulation example of the optimal operation of the ESP lifted oil field by using a MINLP optimizer providing set points to local PI controllers is discussed in Section V. Finally, the conclusion of the research work is described in Section VI.

\section{Model OF THE OIL FIELD}

The ESP lifted oil field consists of modeling the electric submersible pump, electric motor, booster pump and different sections of the oil well including the riser pipe, gathering manifold and transportation lines. Detailed modeling and simulation of the oil field can be found at [9]. In this paper, only the final equations of the model of the oil field have been rewritten similar to the paper by [10], [11] however with few improvements and details. The number of oil wells is taken to be four and the number of transportation lines is taken to be two. The superscript $i$ and $j$ denote the $i^{\text {th }}$ oil well and the $j^{\text {th }}$ transportation pipeline.

TABLE I: WATER CUT VALUES FOR THE WeLlS OF THE OIL FIELD

\begin{tabular}{ccccc}
\hline \hline wells & well 1 & well 2 & well 3 & Well 4 \\
\hline Water Cut & 0.2 & 0.3 & 0.35 & 0.15 \\
\hline \hline
\end{tabular}

\section{A. Motor Model}

The rotor shaft of the electric motor is coupled with the ESP. The rotation of the motor shaft will provide the rotational speed $(\$ \mathrm{f} \$)$ to the ESP. For a given oil well, the speed of the pump can be written as,

$$
\frac{d(2 \pi f)}{d t}=\frac{P}{2 J}\left(T_{e}-T_{l}\right)
$$

Here, $P=2$ is the number of poles of the induction motor, $J$ is the moment of inertia of the rotor shaft and $T_{l}$ is the load torque. The electric torque $\left(T_{e}\right)$ is given by,

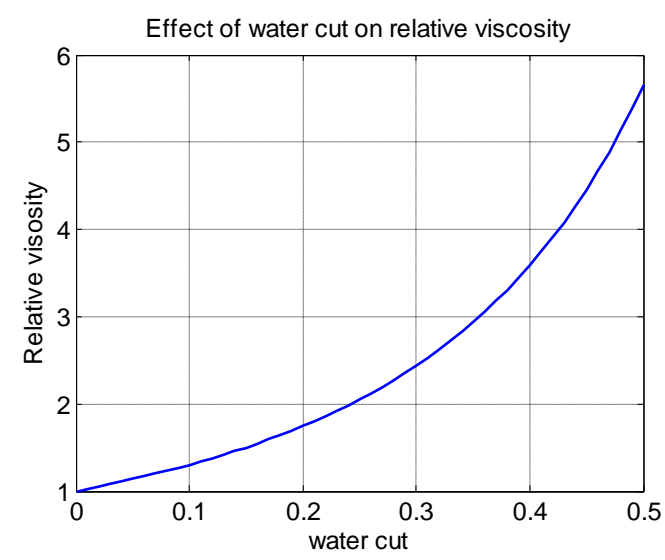

Fig. 1. Relative viscosity of water-in-crude oil dispersion for different water cuts.

$$
T_{e}=\frac{3}{2} \frac{P}{2} \frac{1}{w_{b}}\left(\psi_{d s}^{e} i_{q s}^{e}-\psi_{q s}^{e} i_{d s}^{e}\right)
$$

Here, $w_{b}=60 \mathrm{~Hz}$ is the base speed. Krause's model [12] is used to calculate the d-axis flux linkage in stator $\left(\psi_{d s}^{e}\right)$, q-axis flux linkage in stator $\left(\psi_{q s}^{e}\right)$, q-axis current in stator $\left(i_{q s}^{e}\right)$ and d-axis current in stator $\left(i_{d s}^{e}\right)$.

\section{B. ESP Model}

The head characteristics and the Brake Horse Power (BHP) characteristics of a multi-stage ESP pumping viscous fluid at a given speed are dependent on the viscosity of the fluid. In general, the head produced by the pump decreases if the viscosity of the fluid increases. The BHP of the pump increases with the increase in the viscosity of the fluid being pumped. Viscosity is a function of Water Cut (WC) of the fluid. In [9]-[13], the water cut of each oil well of the field is assumed to be the same. In this paper, we consider that the oil wells of the field have different water cut values as listed in Table I.

The impact of WC on fluid viscosity for water-in-oil dispersion can be expressed using Brinkman formula [14] as,

$$
\eta_{r}=(1-\phi)^{-2.5}
$$

where $\eta_{r}$ is the relative viscosity and $\phi$ is the volume fraction of dispersed water. As the water cut increases, the relative viscosity also increases for water-in-oil dispersion as shown in Fig. 1. If $\eta_{0}$ is the absolute viscosity of pure oil in centiPoise, then the absolute viscosity of the fluid $(\eta)$ with a given water cut is $\eta=\eta_{r} \eta_{0}$. Pump manufacturers publish the pump data for the case of water being pumped. Hydraulic Institute Model (HIM) for viscosity correction [15] is used to correct the pump characteristics for pumping a viscous fluid as detailed in [9]. The kinematic viscosity of the fluid in centiStoke used in HIM is, 


$$
v=\frac{\eta}{S G}
$$

where $S G$ is the specific gravity of the fluid. The head characteristics $\left(H_{e s p}^{i}(Q, f)\right)$ of the $i^{\text {th }}$ ESP after the viscosity correction at any speed $f$ is written as a third order polynomial as,

$$
H_{e s p}^{i}(Q, f)=\frac{\bar{a}_{0}^{i}}{f_{0}^{2}} f^{2}+\frac{\bar{a}_{1}^{i}}{f_{0}} f Q(f)+\bar{a}_{2}^{i} Q^{2}(f)+\frac{\bar{a}_{3}^{i}}{f} f_{0} Q^{3}(f)
$$

Here, $\bar{a}_{0}^{i}, \bar{a}_{1}^{i}, \ldots, \bar{a}_{3}^{i}$ are the polynomial coefficients for the base frequency $f_{0}=60 \mathrm{~Hz}$ and $Q(f)$ is the fluid flow rate through the ESP. The Brake Horse Power (BHP) characteristic $\left(B H P_{e s p}^{i}(Q, f)\right)$ of the $i^{t h}$ ESP after the viscosity correction at any given frequency $f$ is written as a fourth order polynomial,

$$
\begin{aligned}
B H P_{e s p}^{i}(Q, f)=\frac{\hat{a}_{0}^{i}}{f_{0}^{3}} f^{3}+ & \frac{\hat{a}_{1}^{i}}{f_{0}^{2}} f^{2} Q(f)+\frac{\hat{a}_{2}^{i}}{f_{0}} f Q^{2}(f) \\
& +\hat{a}_{3}^{i} Q^{3}(f)+\frac{\hat{a}_{4}^{i}}{f} f_{0} Q^{4}(f)
\end{aligned}
$$

Here, $\hat{a}_{0}^{i}, \hat{a}_{1}^{i}, \ldots, \hat{a}_{4}^{i}$ are the polynomial coefficients for the base frequency $f_{0}=60 \mathrm{~Hz}$. The minimum $\left(Q_{\min }^{i}(f)\right)$ and the maximum $\left(Q_{\max }^{i}(f)\right)$ viscous fluid flow rate through the ESP for any given frequency $f$ can be calculated as,

$$
Q_{\min }^{i}(f)=\frac{f}{f_{0}} Q_{f_{0}, \min }^{i} \quad Q_{\max }^{i}(f)=\frac{f}{f_{0}} Q_{f_{0}, \max }^{i}
$$

Here, $Q_{f_{0}, \min }^{i}$ and $Q_{f_{0} \text {, max }}^{i}$ are the minimum and maximum flow rates through ESP pumping viscous fluid at $f_{0}$. The head generated and the BHP consumed by the pump for different speeds can be calculated using the Affinity laws [16], [17]. Each ESP should be operated inside an operating window. The operating window for an ESP defines the maximum and the minimum allowed speed of the pump and the maximum and minimum flow rate through the pump for a given speed. Each oil well has different water cut value. Since the head and the BHP characteristics of a pump vary with the water cut value of the fluid being pumped, the operating window for each ESP of the oil field will be different as shown in Fig. 2.

The differential equations representing the dynamics of each $i^{\text {th }}$ oil wells are,

$$
\begin{array}{r}
\dot{q}_{l}^{i}=\frac{A_{t}^{i}}{\rho_{l}^{i}\left(L_{r}^{i}+L_{t}^{i}\right)}\left\{P_{w f}^{i}-P_{w h}^{i}\right. \\
+\rho_{l}^{i} g H_{e s p}^{i}\left(q_{l}^{i}, f_{r}^{i}\right)-\rho_{l}^{i} g L_{r}^{i} \\
\left.-\rho_{l}^{i} g L_{t}^{i}-\Delta P_{f}^{r, i}-\Delta P_{f}^{t, i}\right\}
\end{array}
$$

$$
\begin{aligned}
& \dot{P}_{w f}^{i}=\frac{\beta}{A_{r}^{i} L_{r}^{i}}\left[q_{r}^{i}-q_{l}^{i}\right] \\
& \dot{P}_{w h}^{i}=\frac{\beta}{A_{t}^{i} L_{t}^{i}}\left[q_{l}^{i}-q_{c}^{i}\right]
\end{aligned}
$$

$$
\begin{gathered}
\dot{q}_{t r}^{j}=\frac{A_{t r}^{j}}{\rho_{t r}^{j} L_{t r}^{j}}\left[P_{\text {man }}-P_{s}+\rho_{t r}^{j} g H_{b p}^{j}\left(q_{t r}^{j}, f_{b p}^{j}\right)-\Delta P_{f}^{t r, j}\right] \\
\dot{P}_{\text {man }}=\frac{\beta}{A_{m} L_{m}}\left[q_{m a n}^{i n}-\sum_{j=1}^{N_{b p}} q_{t r}^{j}\right]
\end{gathered}
$$

Here, $q_{l}, q_{r}, q_{c}, q_{t r}$ are the average fluid flow rates through a well, from the reservoir into the tubing, through the production choke valve and through the transportation pipeline respectively. $A_{t}, L_{t}, A_{r}, L_{r}$ are the cross sectional areas and lengths of tubing in Section I and II (see Fig. 4) respectively. $A_{t r}, L_{t r}, A_{m}, L_{m}$ are the cross sectional areas and lengths of the transportation pipeline and the gathering manifold respectively. $P_{w f}, P_{w h}, P_{\text {man }}, P_{s}$ are the bottom hole, well head, gathering manifold and separator pressures. $H_{e s p}, H_{b p}$ are the head produced by the ESP and the booster pumps. $\rho_{l}, \rho_{t r}$ are the densities of fluid flowing through the well and the transportation line. $\Delta P_{f}^{r}, \Delta P_{f}^{t}, \Delta P_{f}^{t r}$ are the pressure losses due to friction in Section I and II of the tubing and in the transportation pipeline. $f_{r}^{i}$ is the speed of the pump, $\beta$ is the bulk modulus of the reservoir fluid and $q_{\text {man }}^{\text {in }}$ is the total fluid (including the injected water) flowing into the gathering manifold.

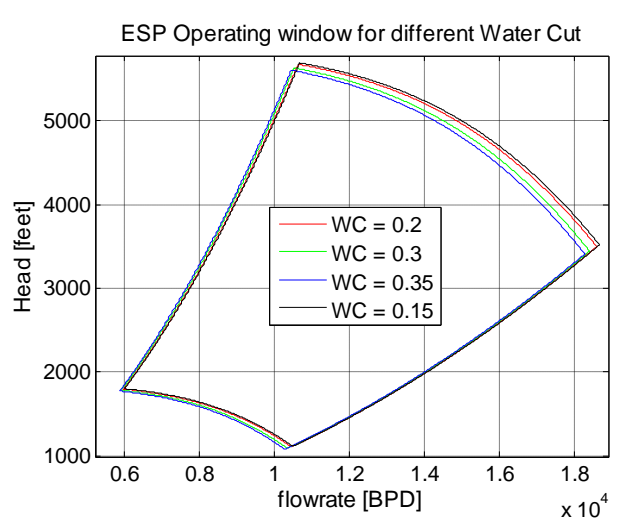

Fig. 2. Operating window of an ESP for different water cuts.

$q_{r}^{i}$ can be expressed using the Productivity Index (PI) model [17] and reservoir pressure $P_{r}$ as,

$$
q_{r}^{i}=P I^{i}\left(P_{r}-P_{w f}^{i}\right)
$$

$q_{c}$ can be expressed using the standard flow equation ANSI/ISA S75.01 developed by Instrument Society of America [18] as, 


$$
q_{c}^{i}=\bar{N}_{6} C_{v}\left(u^{i}\right) \sqrt{\frac{\max \left(P_{w h}^{i}-P_{\operatorname{man}}, 0\right)}{\rho_{l}^{i}}}
$$

Here, $\bar{N}_{6}=N_{6} /\left(3600 \sqrt{10^{5}}\right)$ with $N_{6}=27.3$. The valve characteristics as a function of its opening $\left(C_{v}\left(u^{i}\right)\right)$ is modeled by three linear equations by fitting the data supplied by the choke supplier as,

$$
C_{v}\left(u^{i}\right)=\left\{\begin{array}{cc}
0 & u^{i} \leq 5 \\
0.111 u^{i}-0.556 & 5<u^{i} \leq 50 \\
0.5 u^{i}-20 & u^{i}>50
\end{array}\right.
$$

The pressure loss due to friction is calculated using Darcy-Weisbach formula [19] as,

$$
\Delta P_{f}=\frac{f_{D} L \rho v^{2}}{2 D_{h}}
$$

Here, $\rho$ is the density of fluid flowing through the pipeline, $D_{h}$ is the hydraulic diameter of the pipe and $v$ is the velocity of the fluid. The Darcy friction factor $f_{D}$ can be evaluated using Serghide's explicit approximation to Coolebrook-white equation [20].

\section{OPTIMIZATION OF THE OIL FIELD}

The main task with the optimal operation of an ESP lifted oil field is to calculate and identify the exact number of oil wells to be used for producing a specified total flow rate from the oil field. In addition, the speed of the pump and the production choke valve opening of each selected oil well should be calculated which are non-integer variables. The problem consists of both the integer variables and the continuous variables. Thus, the problem is formulated as a MINLP problem. The MINLP formulation is based on the nonlinear dynamic model of the oil field described in Section II.

The production choke valve of an oil well is placed downstream the ESP in series. For many industrial practices, in general for such a pump and a valve configuration, the valve is normally fully opened to save consumption of power by the upstream pump. It is considered to be wastage of electric power to choke the downstream valve and to run the upstream pump at higher speed to maintain the flow rate. It is economically better to reduce the speed of the pump (if it is possible and is inside its operating window) while fully opening the valve. Moreover, in several research works as in [10], [11] and [13], it has been shown that when all the oil wells in the field are used it is more profitable to keep the production choke valve fully opened. The speed of the pumps in each oil well is used to control the flow rate from the oil well.

In this section, we formulate the pump configuration problem by assuming that the production choke valve for each oil well should be fully opened if the well is selected. If an oil well is not selected, both the speed of the pump and the production choke valves are shut down. Later in Section IV, the advantage of choking the production valve for improved operation of the oil field is described.

\section{A. MINLP Problem Formulation}

The objective function to be maximized is the profit obtained from the oil field. The profit is calculated as the difference between the total income obtained from the crude oil production and the total operational expenses. The total cost of the electric power consumed by the pumps and the cost incurred during the separation process are considered to be the total operational expenses of the oil field. The investment and the maintenance costs are not included in the objective function formulation. The same economic objective function for the oil field has also been used in [10], [11] and [13].

Let $N=4$ be the number of oil wells, $N_{b}=2$ be the number of transportation lines, $C_{0}$ be the unit price of the crude oil, $C_{e}$ be unit price of the electrical power, $C_{s}$ be unit price for running the separator and $W C_{w}^{i}$ be the water cut for each well. Then the objective function in terms of minimization can be written as,

$$
\begin{gathered}
J\left(f_{r}, q_{l}\right)=-C_{0} \sum_{i=1}^{N}\left(1-W C_{w}^{i}\right) q_{l}^{i}+C_{e} \sum_{i=1}^{N} B H P^{i}\left(f_{r}^{i}, q_{l}^{i}\right) \\
+C_{s} \sum_{j=1}^{N_{b}} q_{t r}^{j}\left(q_{l}\right)\left[\frac{\$}{d a y}\right]
\end{gathered}
$$

The first term of the objective function is the value of the crude oil produced from the oil field. The second term is the total cost of electric power consumed by the pumps and the final term is the cost of operating the separator. A binary number $y^{i}$ can be used to denote the state of an $i^{\text {th }}$ oil well. If the oil well is used $y^{i}=1$ and if the oil well is not used $y^{i}=0$.

It is a requirement that the speed of the pump should be within $45 \mathrm{~Hz}$ to $80 \mathrm{~Hz}$ if it is selected. If the well is not selected the speed of the pump should be zero. To incorporate both the selected and not selected conditions in one single equation, the binary variable $y^{i}$ can be used to represent the constraint as,

$$
\begin{aligned}
& f_{r}^{i}-80 y^{i} \leq 0 \\
& -f_{r}^{i}+45 y^{i} \leq 0
\end{aligned}
$$

If the pump is selected ( $\left.y^{i}=1\right)$, the speed of the pump will be between $45 \mathrm{~Hz}$ to $80 \mathrm{~Hz}$ from Eq. 18. If the pump is not selected $\left(y^{i}=0\right)$, the inequality constraints of Eq. 18 will be changed to an equality constraint $f_{r}^{i}=0$. So the use of binary variable $y^{i}$ with the constraint forces the speed of the pump to be zero if the well is not selected.

The production choke valve opening should be $100 \%$ if the 
well is selected and 0 if the well is not selected. It can be expressed as an equality constraint. To maintain consistency in writing the constraints for the optimization problem, the equality constraint for the valve opening along with the binary variable $y^{i}$ can be written as inequality constraints,

$$
\begin{aligned}
& u^{i}-100 y^{i} \leq 0 \\
& -u^{i}+100 y^{i} \leq 0
\end{aligned}
$$

Again, the binary variable $y^{i}$ forces the production choke valve to close completely when the well is not selected and to open fully when it is selected. The fluid flow rate through the pump should be within its minimum and maximum values for a particular pump speed. The minimum and maximum fluid flow rates through the ESP are defined by the maximum tolerable down thrust and the up thrust acting on the vertical pump. Excessive down thrust and up thrust acting on the pump can lead to a mechanical failure of the pump. The minimum/maximum values of the pump flow rate and the pump speed defines the safe working window for the ESP. The fluid flow rate through the pump should be within the operating window for the whole range of allowed pump speeds. The inequality constraint for the flow through the pump is written as,

$$
\begin{aligned}
& q_{l}^{i}-Q_{\max }^{i}\left(f_{r}^{i}\right) y^{i} \leq 0 \\
& -q_{l}^{i}+Q_{\max }^{i}\left(f_{r}^{i}\right) y^{i} \leq 0
\end{aligned}
$$

If an oil well is not selected, the binary variable ensures that the flow rate through the well is zero. Since the minimum and maximum flow rates through the pump have always positive values, the inequality constraints of Eq. 20 ensures that the flow through a well is always positive when the well is selected. If the ESP intake pressure $\left(P_{e s p}^{i n, i}\right)$ is less than the bubble point pressure $\left(P_{b u b}^{i}\right)$, cavitation can occur leading to a physical damage to the pump parts. The ESP intake pressure should be greater than the bubble point pressure.

$$
-P_{e s p}^{i n, i}+P_{b u b}^{i} \leq 0
$$

It is not necessary to use the binary variable $y^{i}$ for the constraint of Eq. 21. If the oil well is not selected, the bottom hole flow pressure $\left(P_{w f}\right)$ will be equal to the reservoir pressure. The ESP intake pressure will be less than the bottom hole flow pressure only by an amount equal to the hydrostatic pressure drop. So, the ESP intake pressure will be sufficiently higher than the bubble point pressure and the constraint of Eq. 21 will be always satisfied. The last constraint for the optimization problem is the total production flow rate $\left(q_{\text {tot }}^{\max }\right)$. The total fluid flowing through both the transportation pipelines should be equal to the specified production flow rate from the oil field. The production flow rate constraints can arise due to limitation of the topside processing facility like the separator capacity or due to changes in the oil production demand. It can be formulated as an equality constraint as,

$$
\sum_{j=1}^{N_{b}} q_{t r}^{j}=q_{t o t}^{\max }
$$

\section{B. Problem Solution}

The MINLP problem of Eq. 17 - Eq. 22 is solved by using the Branch and Bound method [21]. The open source solver BONMIN (Basic Open-source Nonlinear Mixed INteger programming) distributed on COIN-OR (COmputational INfrastructure for Operations Research) [22] under the CPL (Common Public License) is used for solving the MINLP problem. The solver BONMIN can be interfaced to MATLAB by the use of OPTI Toolbox [23] which is a free MATLAB Toolbox for Optimization. BONMIN is a local solver and the solution found by BONMIN may not be a global optimal solution. However, the BB-method of BONMIN solver can also be used for solving the non convex MINLP problems. Options in BONMIN solver allow for solving the root node or each node of the tree with the user specified multiple feasible starting points, saving the best solution found [24]. The feasible starting points are chosen carefully and the start point values for a well shut down condition are also included. This ensures that the solutions found by BONMIN are closer to the global optimal solution. In BB-method, subproblem of the original MINLP problem is constructed at each node. Each subproblem consists of a NonLinear Programming (NLP) relaxation of the MINLP and the integer variables are allowed to take on any real values between their bounds. The relaxed NLP subproblem is then solved using any NLP solver. The search for the optimal solution continues by the divide and conquer method until all the nodes are fathomed. Details about the BB-method are not the objective of this paper and can be read elsewhere as in [21], [25] and [26].

The total production flow rate $\left(q_{\text {tot }}^{\max }\right)$ is varied within a wide range from a low value of $2817 \mathrm{Sm}^{3} /$ day to a high value of $15433 \mathrm{Sm}^{3} /$ day. The MINLP problem is solved for large numbers of specified total production flow rates. For each production flow rate, the number of oil wells and the identity of each well to be used are calculated. The speed of the pump of each selected oil well is chosen optimally so that the pumps consume the least amount of electric power. The optimal results of solving the MINLP problem are listed in Table II.

The easiest way to explain the table is to start from the last section of Table II. The maximum amount of fluid that can be produced from the oil field is $15433 \mathrm{Sm}^{3} /$ day with all the wells running at their top speed of $80 \mathrm{~Hz}$ and all the production choke valves $100 \%$ opened. The corresponding total BHP consumed by all the running pumps is $3759.4 \mathrm{HP}$. Now as the production flow rate or production demand reduces, the speeds of the pumps are reduced. The reduction of the pump speed causes the reduction in the fluid flow rate through each oil well. Obviously, the consumption of electric power also reduces. The reduction of the pump speed for controlling the fluid flow rate continuous until the production flow rate of $8271.6 \mathrm{Sm}^{3} /$ day. For higher production flow rate ( $q_{\text {tot }}^{\max } \geq 8271.6$ ), all the available oil wells are used with their production choke valve fully opened. 
It is interesting to note that the distribution of the speed of the oil wells follows a definite pattern for each production flow rate. As an example, for a production flow rate demand of $12000 \mathrm{Sm}^{3} /$ day, the oil well with the lowest water cut (well 4) is allocated the maximum speed of $67.3932 \mathrm{~Hz}$ and the oil well with the highest water cut (well 3 ) is allocated the minimum speed of $59.1286 \mathrm{~Hz}$. Thus, the speeds of the pumps are distributed with respect to the water cut values of the selected oil wells. As a matter of fact, this pattern can be observed not only for a production flow rate of 12000 $\mathrm{Sm}^{3} /$ day but for the whole flow rate range (including cases with wells shut down) taken into consideration in Table II.

The amount of fluid that flows towards the separator when all the oil wells are used at their lowest permitted speed of 45 $\mathrm{Hz}$ is $8271.6 \mathrm{Sm}^{3} /$ day. Now, if the production flow rate is just slightly reduced to $8200 \mathrm{Sm}^{3} /$ day then one (or more) of the oil wells have to be shut down to fulfill the lower production flow rate. The focus of interest is to find out how many and which of the oil wells should be turned on and which of them should be turned off. As can be seen from Table II, for $q_{\text {tot }}^{\max }=8200 \mathrm{Sm}^{3} /$ day one oil well should be shut down. The oil well which is shut down is well 3 . The speed of the pump and the valve opening of well 3 are both equal to zero. Another point of interest is the power consumption and the speed of the remaining three running wells. The total power consumed by the pumps is $732.6974 \mathrm{HP}$ which is greater than the power consumed when all four wells are running for the case of $q_{\text {tot }}^{\max }=8271.6 \mathrm{Sm}^{3} / \mathrm{day}$. So the power consumption increases even if $q_{\text {tot }}^{\max }$ has decreased. It can be explained by observing the way the pump speeds for the remaining oil wells are distributed. When well 3 is shut down, it does not produce any fluid causing a reduction in the total fluid flow rate. To compensate for this reduced flow rate, the remaining oil wells have to produce more by increasing their pump speed. The speeds of the pump of well 1, well 2 and well 4 are increased from $45 \mathrm{~Hz}$ each to a new higher value of 51.6601 $\mathrm{Hz}, 48.0550 \mathrm{~Hz}$ and $53.5424 \mathrm{~Hz}$ respectively. The relationship between the BHP and the pump speed is given by Eq. 6 . When the pump speed and the flow rate through a pump increase, the BHP of the pump also increases as shown in Fig. 3.

TABLE II: OPTIMAL OPERATION OF AN ESP LIFTED OIL FIELD FOR DIFFERENT PRODUCTION FLOW RATES

\begin{tabular}{|c|c|c|c|c|c|c|c|c|c|c|c|c|c|c|c|c|c|}
\hline \multirow{2}{*}{$\begin{array}{l}\text { Production } \\
\text { flow rate } \\
\mathrm{Sm}^{3} / \mathrm{day} \\
q_{\max }^{\max }\end{array}$} & \multirow[t]{2}{*}{$\begin{array}{c}\text { Total BHP } \\
\text { [HP] }\end{array}$} & \multicolumn{4}{|c|}{$\begin{array}{c}\text { Optimsl pump speed } \\
{[\mathrm{Hz}]} \\
\end{array}$} & \multicolumn{4}{|c|}{$\begin{array}{c}\text { Well Selection } \\
\text { [y'] }\end{array}$} & \multicolumn{4}{|c|}{$\begin{array}{c}\text { Valve openings } \\
{[\%]} \\
\end{array}$} & \multicolumn{4}{|c|}{$\begin{array}{l}\text { Optimal fluid flow rate } \\
\qquad \operatorname{Sx}^{3} / d a y\end{array}$} \\
\hline & & Well 1 & Well 2 & Well 3 & Well 4 & Well 1 & Well 2 & Well 3 & Well 4 & Well 1 & Well 2 & Well 3 & Well 4 & Well 1 & Well 2 & Well 3 & Well 4 \\
\hline 2817 & 162.6287 & 0 & 0 & 0 & 45 & 0 & 0 & 0 & 1 & 0 & 0 & 0 & 100 & 0 & 0 & 0 & 1656.8 \\
\hline 2900 & 176.1265 & 0 & 0 & 0 & 46.2250 & 0 & 0 & 0 & i & 0 & 0 & 0 & 100 & 0 & 0 & 0 & 1705.9 \\
\hline 3000 & 193.2760 & 0 & 0 & 0 & 47.6879 & 0 & 0 & 0 & 1 & 0 & 0 & 0 & 100 & 0 & 0 & 0 & 1764.7 \\
\hline 3100 & 211.3951 & 0 & 0 & 0 & 49.1432 & 0 & 0 & 0 & 1 & 0 & 0 & 0 & 100 & 0 & 0 & 0 & 1823.6 \\
\hline 3500 & 303.7597 & 0 & 0 & 0 & 55.4573 & 0 & 0 & 0 & 1 & 0 & 0 & 0 & 100 & 0 & 0 & 0 & 2058.9 \\
\hline 3800 & 388.7059 & 0 & 0 & 0 & 60.2082 & 0 & 0 & 0 & 1 & 0 & 0 & 0 & 100 & 0 & 0 & 0 & 2235.3 \\
\hline 4000 & 453.4675 & 0 & 0 & 0 & 63.3814 & 0 & 0 & 0 & 1 & 0 & 0 & 0 & 100 & 0 & 0 & 0 & 2353 \\
\hline 4500 & 645.5253 & 0 & 0 & 0 & 71.2995 & 0 & 0 & 0 & 1 & 0 & 0 & 0 & 100 & 0 & 0 & 0 & 2647.2 \\
\hline 5100 & 909.6851 & 0 & 0 & 0 & 80 & 0 & 0 & 0 & 1 & 0 & 0 & 0 & 100 & 0 & 0 & 0 & 3000 \\
\hline 5170.2 & 328.6792 & 45 & 0 & 0 & 45 & 1 & 0 & 0 & 1 & 100 & 0 & 0 & 100 & 1524.7 & 0 & 0 & 1606.3 \\
\hline 5200 & 333.5266 & 45 & 0 & 0 & 45.4433 & 1 & 0 & 0 & $i$ & 100 & 0 & 0 & 100 & 1524 & 0 & 0 & 1624.5 \\
\hline 5500 & 386.1720 & 46.5118 & 0 & 0 & 48.4453 & $i$ & 0 & 0 & 1 & 100 & 0 & 0 & 100 & 1581.9 & 0 & 0 & 1746.5 \\
\hline 5900 & 460.5327 & 49.3224 & 0 & 0 & 51.3949 & i & 0 & 0 & 1 & 100 & 0 & 0 & 100 & 1700 & 0 & 0 & 1870.6 \\
\hline 6000 & 482.5577 & 50.1001 & 0 & 0 & 52.2006 & $i$ & 0 & 0 & 1 & 100 & 0 & 0 & 100 & 1729.6 & 0 & 0 & 1901.6 \\
\hline 6500 & 602.4401 & 53.9643 & 0 & 0 & 56.2062 & 1 & 0 & 0 & 1 & 100 & 0 & 0 & 100 & 1877.2 & 0 & 0 & 2056.7 \\
\hline 7000 & 739.3544 & 57.7946 & 0 & 0 & 60.1801 & i & 0 & 0 & 1 & 100 & 0 & 0 & 100 & 2024.9 & 0 & 0 & 22119 \\
\hline 7100 & 768.8736 & 58.5573 & 0 & 0 & 60.9716 & i & 0 & 0 & 1 & 100 & 0 & 0 & 100 & 2054.4 & 0 & 0 & 22429 \\
\hline 7148 & 498.5338 & 45 & 45 & 0 & 45 & 1 & 1 & 0 & 1 & 100 & 100 & 0 & 100 & 1447.8 & 1588.7 & 0 & 1533.7 \\
\hline 7200 & 508.1734 & 45 & 45 & 0 & 45.8683 & $i$ & i & 0 & i & 100 & 100 & 0 & 100 & 1444.6 & 15859 & 0 & 1569.6 \\
\hline 7500 & 568.8355 & 47.1174 & 45 & 0 & 48.8515 & $i$ & 1 & 0 & 1 & 100 & 100 & 0 & 100 & 1522.4 & 1569 & 0 & 1686.8 \\
\hline 7800 & 635.7732 & 49.2626 & 45.8529 & 0 & 51.0712 & $i$ & 1 & 0 & 1 & 100 & 100 & 0 & 100 & 1602.2 & 1590.4 & 0 & 1770.6 \\
\hline 7900 & 659.2024 & 49.8635 & 46.4053 & 0 & 51.6901 & i & 1 & 0 & 1 & 100 & 100 & 0 & 100 & 1623.7 & 1609.8 & 0 & 1793.2 \\
\hline 8000 & 683.1600 & 50.4634 & 46.9245 & 0 & 52.3343 & 1 & 1 & 0 & 1 & 100 & 100 & 0 & 100 & 1645.2 & 1627.7 & 0 & 1817 \\
\hline 8200 & 732.6974 & 51.6601 & 48.0550 & 0 & 53.5425 & $i$ & 1 & 0 & 1 & 100 & 100 & 0 & 100 & 1688.2 & 1668 & 0 & 1861 \\
\hline 8271.6 & 661.619 & 45 & 45 & 45 & 45 & 1 & 1 & 1 & 1 & 100 & 100 & 100 & 100 & 1370.3 & 1519.9 & 1130.8 & 1460.9 \\
\hline 8500 & 709.0835 & 46.3422 & 45 & 45 & 47.8402 & 1 & $\mathrm{i}$ & $\mathrm{i}$ & 1 & 100 & 100 & 100 & 100 & 1417.1 & 1503.9 & 1110.3 & 1578.6 \\
\hline 9000 & 829.911 & 50.1264 & 46.7368 & 45.1519 & 51.7643 & 1 & 1 & 1 & 1 & 100 & 100 & 100 & 100 & 1561.4 & 1550.9 & 1059.2 & 1729.8 \\
\hline 9500 & 965.6466 & 52.6885 & 49.1039 & 47.5715 & 54.3927 & $i$ & 1 & 1 & 1 & 100 & 100 & 100 & 100 & 1648 & 1628.8 & 1144 & 1820.9 \\
\hline 10000 & 1114.4 & 55.2325 & 51.4579 & 49.9658 & 57.0045 & i & 1 & 1 & 1 & 100 & 100 & 100 & 100 & 1734.7 & 1706.7 & 1218.9 & 1912.1 \\
\hline 11000 & 14529 & 60.2775 & 56.1334 & 54.6914 & 62.1870 & $i$ & 1 & 1 & 1 & 100 & 100 & 100 & 100 & 1908.1 & 18622 & 1369.1 & 2094.2 \\
\hline 12000 & 1849.4 & 65.3373 & 60.8303 & 59.1286 & 67.3932 & $i$ & 1 & 1 & 1 & 100 & 100 & 100 & 100 & 2084.5 & 2020.4 & 1508.3 & 2279.6 \\
\hline 13000 & 23099 & 70.3171 & 65.4608 & 63.7224 & 72.5189 & $i$ & 1 & 1 & 1 & 100 & 100 & 100 & 100 & 2258.8 & 2176.5 & 1655.6 & 2462.7 \\
\hline 14000 & 2837.8 & 75.2679 & 70.0709 & 68.2763 & 77.06195 & i & 1 & 1 & 1 & 100 & 100 & 100 & 100 & 2433 & 2332.4 & 1802.9 & 26459 \\
\hline 15000 & 3444.6 & 80 & 76.4698 & 74.4116 & 80 & 1 & 1 & 1 & 1 & 100 & 100 & 100 & 100 & 2596.9 & 2582.3 & 20419 & 2691.3 \\
\hline 15433 & 3759.4 & 80 & 80 & 80 & 80 & 1 & $i$ & i & $i$ & 100 & 100 & 100 & 100 & 2560.5 & 2729.6 & 2307.1 & 2656.3 \\
\hline
\end{tabular}

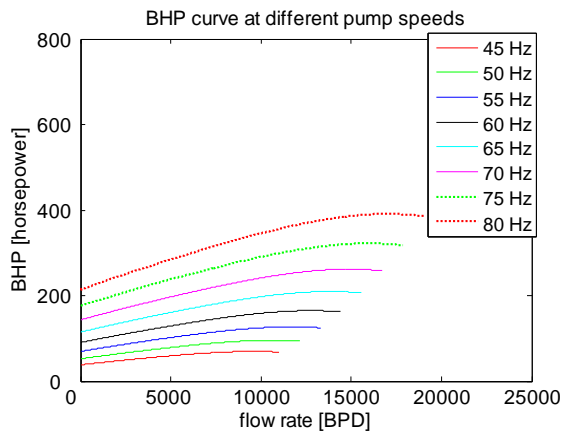

Fig. 3. Power consumed by the pump for different frequencies.

When the production flow rate is lowered below 8200
$\mathrm{Sm}^{3} /$ day until $7148 \mathrm{Sm}^{3} /$ day, only three oil wells will be used and well 3 will always be shut down. The speed of the pumps of the active oil wells are reduced to control the fluid flow rate and the total BHP reduces as the production demand decreases towards $7148 \mathrm{Sm}^{3} /$ day. The amount of fluid flowing towards the separator through the transportation line is $7148 \mathrm{Sm}^{3} /$ day when the active oil wells 1,2 and 4 are each running at their lowest allowed speed of $45 \mathrm{~Hz}$ and with their valves $100 \%$ opened. As mentioned before, if the production demand reduces just slightly to $7100 \mathrm{Sm}^{3} /$ day, then some wells have to be shut down. In this case, well 2 and well 3 are shut down. The total power consumed by the pumps is 768.8736 HP which is greater than 498.5338 HP for the case 
of $q_{t o t}^{\max }=7148 \mathrm{Sm}^{3} /$ day. The speed of the pumps of well 1 and well 4 are respectively $58.5573 \mathrm{~Hz}$ and $60.9716 \mathrm{~Hz}$ which are both greater than $45 \mathrm{~Hz}$ (for $q_{\text {tot }}^{\max }=7100$ $\mathrm{Sm}^{3} /$ day). This causes higher consumption of power for fulfilling comparatively lower flow rate.

With only well 1 and well 4 as the active oil wells, as the production flow rate is reduced from $7100 \mathrm{Sm}^{3} /$ day, the speeds of the active wells are also reduced and the total BHP is decreased. The distribution of the speed among the active oil wells still follow their water cut values with lower water cut well being given the higher speed. When well 1 and well 4 are both at $45 \mathrm{~Hz}$ with the production choke valves at their fullest and well 2 and well 4 shut down, the amount of fluid produced from the field is $5170.2 \mathrm{Sm}^{3} /$ day. When the production flow rate is slightly reduced to $5100 \mathrm{Sm}^{3} /$ day, in addition to well 2 and well 3, well 1 is also shut down. From a production demand of $5100 \mathrm{Sm}^{3} /$ day and below, only well 4 is active and the remaining three oil wells are shut down. As the production flow rate decreases with only well 4 being active, the speed of the pump is also reduced to control the flow rate through the well. The maximum fluid that can be produced from the oil field with only one well running at its lowest permitted speed of $45 \mathrm{~Hz}$ is $2817 \mathrm{Sm}^{3} /$ day.

On closer analysis of the results obtained by solving the MINLP problem, a pattern on how the wells are selected can be observed. From Table II, it can be seen that the first oil well to be shut down is well 3. The second oil to be shut down is well 2 followed by well 1 . The water cut of well 3 is higher than well 2 which in turn is higher than well 1 . The oil with the lowest water cut is well 4 which is the only well always running for the whole range of production flow rate. This means that the selection of the oil wells for shutting down is dependent on the water cut value of the wells. For higher production rate, it is profitable to run all the oil wells of the field and for the lower production rates, it is profitable to run alone the oil well with lowest water cut. An oil well having the lowest water cut produces the maximum pure crude oil per unit volume. During the minimization of the objective function of Eq. 17, because of much higher value of crude oil compared to the cost of electricity and cost of separator operation, it is more profitable to use the oil wells with lowest water cut as much as possible. From Table II, well 4 with the lowest water cut is used the most. The second most used well is well 1 with second lowest water cut value and so on.

Not only is the selection of the oil wells to be used based on water cut, the distribution of the speed among the selected oil wells is also based on water cut as explained earlier. It is economically beneficial to pump out more from among the selected oil wells which has the lowest water cut. Thus, greater speed for this well should be allocated followed by the speed of the well with second lowest water cut value and so on.

TABLE III: IMPROVED OPERATION OF THE ESP LIFTED OIL FIELD FOR DIFFERENT PRODUCTION FLOW RATES

\begin{tabular}{|c|c|c|c|c|c|c|c|c|c|c|c|c|c|c|c|c|c|}
\hline \multirow{2}{*}{$\begin{array}{c}\text { Production } \\
\text { flow rate } \\
\mathrm{Sm}^{3} / \mathrm{day} \\
q_{\text {fot }}^{\max }\end{array}$} & \multirow[t]{2}{*}{$\begin{array}{c}\text { Total BHP } \\
\text { [HP] } \\
\end{array}$} & \multicolumn{4}{|c|}{$\begin{array}{c}\text { Optimsl punus speed } \\
{[\mathrm{Hz}]}\end{array}$} & \multicolumn{4}{|c|}{$\begin{array}{c}\text { Well Selection } \\
{\left[y^{\prime}\right]}\end{array}$} & \multicolumn{4}{|c|}{$\begin{array}{c}\text { Valve openings } \\
{[\%]}\end{array}$} & \multicolumn{4}{|c|}{$\begin{array}{c}\text { Optimal fluid flow rate } \\
\mathrm{Sm}^{3} / \mathrm{day}\end{array}$} \\
\hline & & Well 1 & Well 2 & Well 3 & Well 4 & Well 1 & Well 2 & Well 3 & Well 4 & Well 1 & Well 2 & Well 3 & Well 4 & Well 1 & Well 2 & Well 3 & Well 4 \\
\hline 1632.7 & 144.7941 & 0 & 0 & 0 & 45 & 0 & 0 & 0 & 1 & 0 & 0 & 0 & 54 & 0 & 0 & 0 & 960.589 \\
\hline 1800 & 149.5513 & 0 & 0 & 0 & 45 & 0 & 0 & 0 & 1 & 0 & 0 & 0 & 56.0670 & 0 & 0 & 0 & 1058.9 \\
\hline 2200 & 158.9588 & 0 & 0 & 0 & 45 & 0 & 0 & 0 & 1 & 0 & 0 & 0 & 67.6780 & 0 & 0 & 0 & 1294.2 \\
\hline 2817 & 162.6287 & 0 & 0 & 0 & 45 & 0 & 0 & 0 & 1 & 0 & 0 & 0 & 100 & 0 & 0 & 0 & 1656.8 \\
\hline 2900 & 176.1265 & 0 & 0 & 0 & 46.2250 & 0 & 0 & 0 & 1 & 0 & 0 & 0 & 100 & 0 & 0 & 0 & 1705.9 \\
\hline 3000 & 193.2760 & 0 & 0 & 0 & 47.6879 & 0 & 0 & 0 & 1 & 0 & 0 & 0 & 100 & 0 & 0 & 0 & 1764.7 \\
\hline 3100 & 211.3951 & 0 & 0 & 0 & 49.1432 & 0 & 0 & 0 & 1 & 0 & 0 & 0 & 100 & 0 & 0 & 0 & 1823.6 \\
\hline 3500 & 300.8168 & 45 & 0 & 0 & 45 & 1 & 0 & 0 & 1 & 55.2146 & 0 & 0 & 59.3681 & 951 & 0 & 0 & 1163.7 \\
\hline 3800 & 306.9737 & 45 & 0 & 0 & 45 & $i$ & 0 & 0 & 1 & 55.3301 & 0 & 0 & 65.6619 & 951 & 0 & 0 & 1340.3 \\
\hline 4000 & 309.4439 & 45 & 0 & 0 & 45 & 1 & 0 & 0 & 1 & 55.4085 & 0 & 0 & 72.5702 & 951 & 0 & 0 & 1457.9 \\
\hline 4500 & 316.4126 & 45 & 0 & 0 & 45 & $i$ & 0 & 0 & 1 & 59.3066 & 0 & 0 & 100 & 1090.2 & 0 & 0 & 1621.0 \\
\hline 5100 & 328.3482 & 45 & 0 & 0 & 45 & $i$ & 0 & 0 & 1 & 87.0687 & 0 & 0 & 100 & 1479.2 & 0 & 0 & 1607.8 \\
\hline 5170.2 & 328.6792 & 45 & 0 & 0 & 45 & $i$ & 0 & 0 & 1 & 100 & 0 & 0 & 100 & 1524.7 & 0 & 0 & 1606.3 \\
\hline 5200 & 333.5266 & 45 & 0 & 0 & 45.4433 & $i$ & 0 & 0 & 1 & 100 & 0 & 0 & 100 & 1524 & 0 & 0 & 1624.5 \\
\hline 5500 & 386.1720 & 46.5118 & 0 & 0 & 48.4453 & 1 & 0 & 0 & 1 & 100 & 0 & 0 & 100 & 1581.9 & 0 & 0 & 1746.5 \\
\hline 5900 & 460.5327 & 49.3224 & 0 & 0 & 51.3949 & 1 & 0 & 0 & 1 & 100 & 0 & 0 & 100 & 1700 & 0 & 0 & 1870.6 \\
\hline 6000 & 474.7474 & 45 & 45 & 0 & 45 & 1 & 1 & 0 & 1 & 65.8684 & 54.7285 & 0 & 100 & 1235.4 & 941.4 & 0 & 1591.5 \\
\hline 6500 & 481.4515 & 45 & 45 & 0 & 45 & $i$ & $i$ & 0 & 1 & 57.3944 & 100 & 0 & 100 & 977.8 & 1621.2 & 0 & 1568.1 \\
\hline 7000 & 496.2412 & 45 & 45 & 0 & 45 & i & i & 0 & 1 & 76.9191 & 100 & 0 & 100 & 1339.6 & 1596.6 & 0 & 1542.0 \\
\hline 7100 & 497.9386 & 45 & 45 & 0 & 45 & 1 & $i$ & 0 & 1 & 88.9581 & 100 & 0 & 100 & 1412.6 & 1591.3 & 0 & 1536.5 \\
\hline 7148 & 498.5338 & 45 & 45 & 0 & 45 & $i$ & $i$ & 0 & 1 & 100 & 100 & 0 & 100 & 1447.8 & 1588.7 & 0 & 1533.7 \\
\hline 7200 & 508.1734 & 45 & 45 & 0 & 45.8683 & $i$ & i & 0 & 1 & 100 & 100 & 0 & 100 & 1444.6 & 15859 & 0 & 1569.6 \\
\hline 7500 & 568.8355 & 47.1174 & 45 & 0 & 48.8515 & $i$ & $i$ & 0 & 1 & 100 & 100 & 0 & 100 & 1522.4 & $1569^{\circ}$ & 0 & 1686.8 \\
\hline 7800 & 635.7732 & 49.2626 & 45.8529 & 0 & 51.0712 & 1 & 1 & 0 & 1 & 100 & 100 & 0 & 100 & 1602.2 & 1590.4 & 0 & 1770.6 \\
\hline 7900 & 649.0904 & 45 & 45 & 45 & 45 & 1 & 1 & 1 & 1 & 73.4191 & 100 & 64.3758 & 100 & 1246.3 & 1544.7 & 934.8 & 1487.2 \\
\hline 8000 & 651.4569 & 45 & 45 & 45 & 45 & $i$ & $i$ & $i$ & 1 & 83.0727 & 100 & 64.8084 & 100 & 1321.9 & 1538.1 & 935 & 1480.1 \\
\hline 8200 & 658.5128 & 45 & 45 & 45 & 45 & i & i & i & 1 & 100 & 100 & 77.8666 & 100 & 1376.0 & 1525.0 & 1054.3 & 1466.3 \\
\hline 8271.6 & 661.619 & 45 & 45 & 45 & 45 & $i$ & i & $i$ & 1 & 100 & 100 & 100 & 100 & 1370.3 & 15199 & 1130.8 & 1460.9 \\
\hline 8500 & 709.0835 & 46.3422 & 45 & 45 & 47.8402 & $i$ & i & i & 1 & 100 & 100 & 100 & 100 & 1417.1 & 1503.9 & 1110.3 & 1578.6 \\
\hline 9000 & 829.911 & 50.1264 & 46.7368 & 45.1519 & 51.7643 & $i$ & i & i & 1 & 100 & 100 & 100 & 100 & 1561.4 & 1550.9 & 1069.2 & 1729.8 \\
\hline 9500 & 965.6466 & 52.6885 & 49.1039 & 47.5715 & 54.3927 & 1 & $i$ & $i$ & 1 & 100 & 100 & 100 & 100 & 1648 & 1628.8 & 1144 & 1820.9 \\
\hline 10000 & 1114.4 & 55.2325 & 51.4579 & 49.9658 & 57.0045 & 1 & i & $\mathrm{i}$ & 1 & 100 & 100 & 100 & 100 & 1734.7 & 1706.7 & 1218.9 & 1912.1 \\
\hline 11000 & 1452.9 & 60.2775 & 56.1334 & 54.6914 & 62.1870 & $i$ & i & $i$ & 1 & 100 & 100 & 100 & 100 & 1908.1 & 1862.2 & 1369.1 & 2094.2 \\
\hline 12000 & 1849.4 & 65.3373 & 60.8303 & 59.1286 & 67.3932 & $i$ & i & i & 1 & 100 & 100 & 100 & 100 & 2084.5 & 2020.4 & 1508.3 & 2279.6 \\
\hline 13000 & 2309.9 & 70.3171 & 65.4608 & 63.7224 & 72.5189 & $i$ & i & $i$ & 1 & 100 & 100 & 100 & 100 & 2258.8 & 2176.5 & 1655.6 & 2462.7 \\
\hline 14000 & 2837.8 & 75.2679 & 70.0709 & 68.2763 & 77.6195 & $i$ & $i$ & $i$ & 1 & 100 & 100 & 100 & 100 & 2433 & 2332.4 & 1802.9 & 2645.9 \\
\hline 15000 & 3444.6 & 80 & 76.4698 & 74.4116 & 80 & 1 & 1 & $\mathrm{i}$ & 1 & 100 & 100 & 100 & 100 & 2596.9 & 2582.3 & 20419 & 2691.3 \\
\hline 15433 & 3759.4 & 80 & 80 & 80 & 80 & 1 & 1 & $i$ & 1 & 100 & 100 & 100 & 100 & 2560.5 & 2729.6 & 2307.1 & 2656.3 \\
\hline
\end{tabular}

\section{IMPROVED OPERATION WITH VALVE CHOKING}

In the previous section, the production choke valves are assumed to be always fully opened and MINLP was solved to calculate the number and identity of the active wells and their corresponding pump speeds. This section describes how the production choke valves can also be manipulated for improving the operation of the ESP lifted oil field. Instead of always keeping the valves fully opened, they can also be used under certain conditions to properly regulate the flow through the oil well. In other words, choking of the production choke valves can improve the operation of the 
field significantly.

The objective function to be minimized is similar to the one described in Eq. 17 in Section III-A i.e. the interest is on maximizing the profit by minimizing the total operational expenses of the oil field. All the constraints of the MINLP problem remains the same as described in Eq. 18 - Eq. 22 except the constraint for the production choke valve opening in Eq. 19. Since, the production choke valves are allowed to be used for regulating the flow through the wells, it can take any values from fully closed $(0 \%)$ to fully opened (100\%). This condition can be expressed as inequality constraints as,

$$
\begin{aligned}
& u^{i}-100 y^{i} \leq 0 \\
& -u^{i}+0 y^{i} \leq 0
\end{aligned}
$$

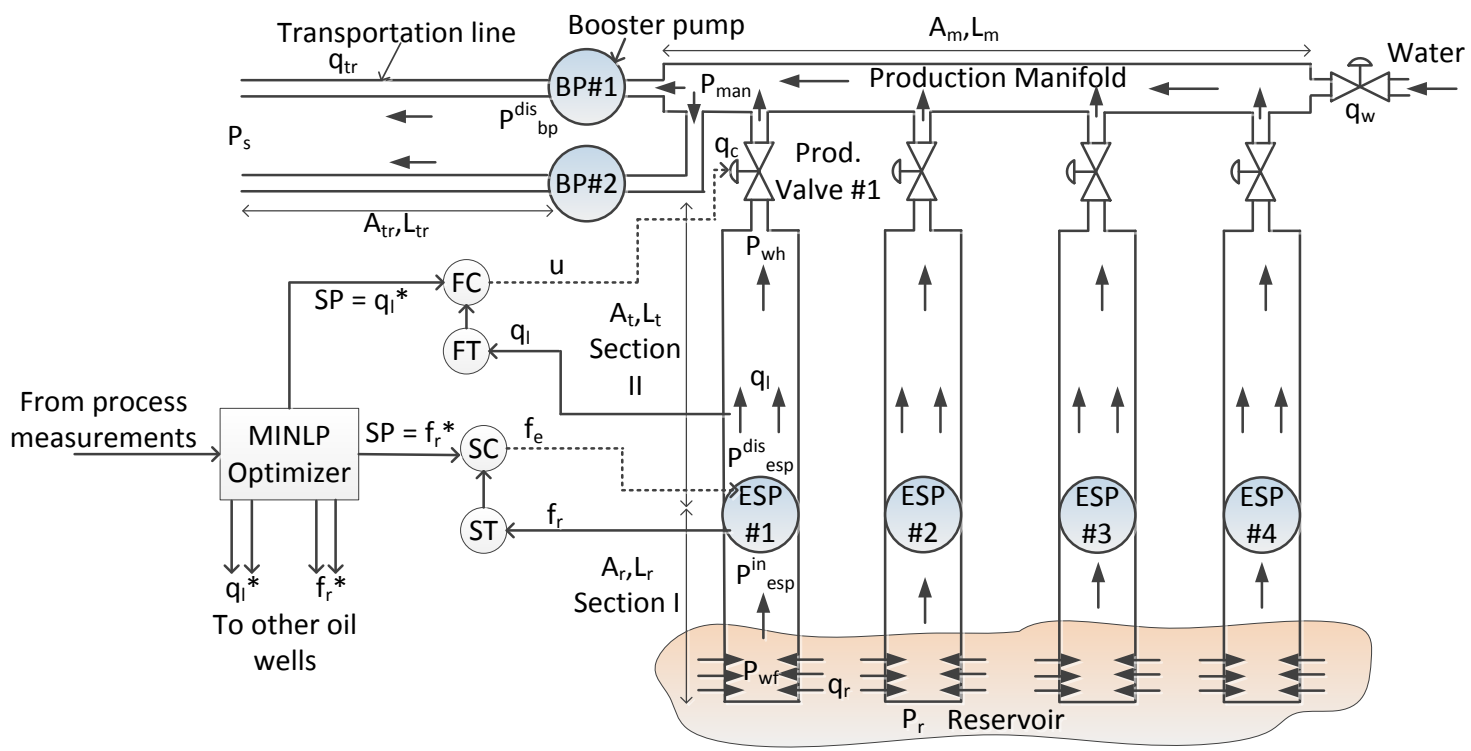

Fig. 4. Optimal control structure for ESP lifted oil field with MINLP optimizer.

(Figure of only the oil field excluding the control structure is the courtesy of Statoil Research Center, Porsgrunn, Norway).

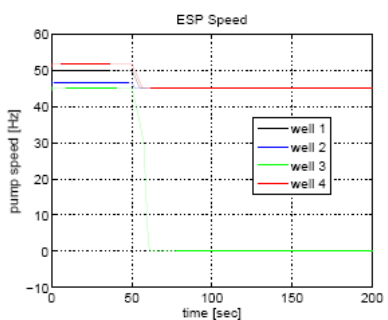

(a) ESP speed

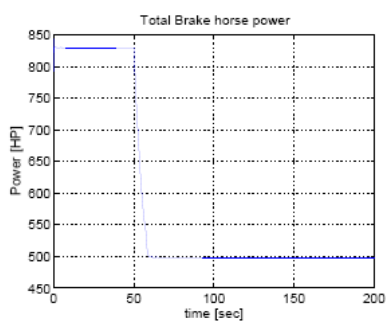

(c) Total power consumed

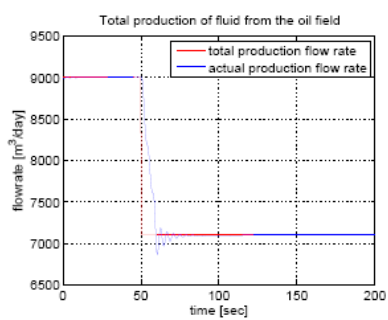

(e) Total fluid flowing to the separator

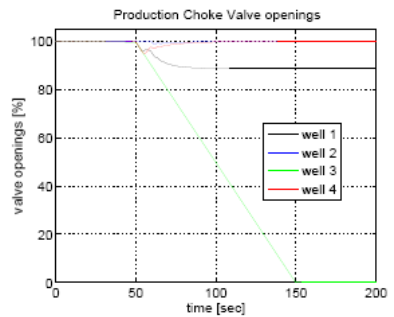

(b) Production choke valve opening

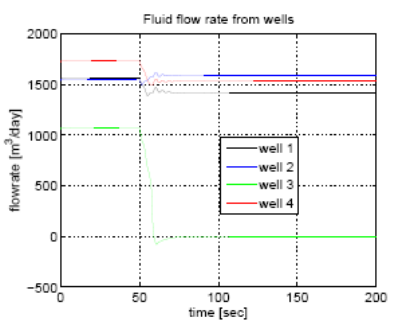

(d) Fluid flow rate through wells

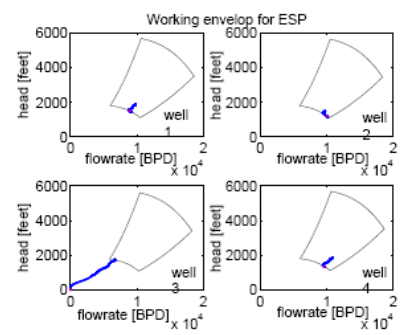

(f) Operating window
Fig. 5. Optimal operation of an ESP lifted oil field.

If the well is not selected, the production choke valve should be fully closed. As explained before, this is done by using the binary variable $y^{i}$. When $y^{i}=0$, the inequality equations of Eq. 23 changes into equality constraint $u^{i}=0$. The newly formulated MINLP problem of Eq. 17, Eq. 18 and Eq. 20 - Eq. 23 is solved using the same BONMIN solver with BB-method as in Section III-B for a wide range of production flow rates. The results of the simulation are listed in Table III.

Table III looks very similar to II. However, there are also some interesting differences in between these two tables. Description of Table III is also started from the bottom row of the table and moving upwards. For higher production flow rate capacities from $15433 \mathrm{Sm}^{3} /$ day to $8271.6 \mathrm{Sm}^{3} /$ day, the results in both the tables are identical. Thus, the discussion remains the same as already described in Section III-B i.e. the production flow rate capacities are controlled by controlling the speed of the pumps and with $u^{i}=100 \%$. When all the four oil wells are running at $45 \mathrm{~Hz}$ with each production choke valve fully opened, the production flow rate is 8271.6 $\mathrm{Sm}^{3} /$ day. In Table II when the production flow rate is slightly reduced to $8200 \mathrm{Sm}^{3} /$ day, well 3 is shut down and the total power consumption is 732.6974 HP. However, the results from Table III indicates that for $q_{t o t}^{\max }=8200 \mathrm{Sm}^{3} /$ day, instead of shutting down well 3 , the production choke valve opening of well 3 can be choked to $77.8666 \%$ opening to control the reduced flow rate. The well can still be active at its lowest permitted operating speed of $45 \mathrm{~Hz}$ and it is not necessary to shut down the well. The total power consumed by the pumps when the valve of well 3 is choked is 658.5128 HP which is less than 732.6974 HP when well 3 is shut down. Both configurations however are producing the same amount of fluid ( $8200 \mathrm{Sm}^{3} /$ day) from the field. So, for producing the 
same amount of oil from the field, the production choke valve can be choked while the wells are still running and this configuration is economically more beneficial than shutting down the oil wells.

If the production flow rate is decreased below 8200 $\mathrm{Sm}^{3} /$ day, the choking of the valves with all wells turned on can still be continued for lower flow rates. More than one oil well can participate in reducing the flow rate by choking its valve as shown in Table III. As an example for $q_{t o t}^{\max }=8000$ $\mathrm{Sm}^{3} /$ day, the production choke valves of well 1 as well as well 3 are reduced to $83.0727 \%$ and $64.8084 \%$ respectively. An interesting thing to note is while the valves are being choked for regulating the lower flow rates, the pump speed of each active well are at the lowest speed of $45 \mathrm{~Hz}$ and are not changing. This is true because if the valves are more choked and at the same time if the speed of the pumps are increased above $45 \mathrm{~Hz}$ to maintain the flow rate, the pumps will consume unnecessarily more power. In other words, it is a waste of electrical energy to choke a valve located downstream a pump and then to increase the speed of the pump to maintain the flow rate.

However, the choking of the production choke valves while still keeping the wells active will be beneficial only for a while as the production flow rate decreases more. From Table III it can be seen that for $q_{\text {tot }}^{\max }=7800 \mathrm{Sm}^{3} /$ day, well 3 is shut down instead of further choking the production choke valves and running all the four wells. The total consumption of power with well 3 shut down is $635.7732 \mathrm{HP}$. If the production choke valves are choked and all the four wells are kept running, it will still be possible to fulfill the same production flow rate capacity but the total consumption of power will be $646.3128 \mathrm{HP}$. Clearly, it is more profitable to shut down well 3 . When well 3 is shut down, there will be a loss of fluid production from this well. To compensate this loss, the speed of the pumps of the remaining active wells ( well 1, well 2 and well 4) are increased to $49.2626 \mathrm{~Hz}$, $45.8529 \mathrm{~Hz}$ and $51.0712 \mathrm{~Hz}$ respectively from their previous speed of $45 \mathrm{~Hz}$ each. At the same time, the choke valve openings are increased to their full opening of $100 \%$ from their previous choked positions.

Now once again but with a well shut down (well 3), the production flow rate capacities below $7800 \mathrm{Sm}^{3} /$ day can be controlled by controlling the speed of the pumps of the active oil wells and at the same time by keeping the choke valves at their maximum opening (without performing any choking actions). Pump speed control with $u^{i}=100 y^{i} \%$ can be continued until all the active oil wells reach to their minimum allowed speed of $45 \mathrm{~Hz}$ for which the total production flow rate is $7148 \mathrm{Sm}^{3} /$ day. Here, the binary variable $y^{i}$ is used to denote that the valve opening of the inactive well 3 is $0 \%$. For a slight lower capacity of $7100 \mathrm{Sm}^{3} /$ day, in Table II, two wells (well 2 and well 3) are shut down and the total power consumption is 768.8732 HP. In Table III, it is shown that the same capacity (or in other words the same amount of crude oil production) can be fulfilled by keeping well 2 still running at $45 \mathrm{~Hz}$ and choking the production choke valve of well 1 to $88.9581 \%$. The total power consumption due to valve choking is $497.9386 \mathrm{HP}$ which is significantly lower than the case when well 2 and well 3 are shut down.

The control of the production flow rate below 7100 $\mathrm{Sm}^{3} /$ day can now be performed by choking the valves of the active oil wells (well 1, well 2 and well 4) while keeping the speed of the pumps of the active wells at their lowest allowed speed of $45 \mathrm{~Hz}$. The valve choke control with $f_{r}^{i}=45 y^{i} \mathrm{~Hz}$ can be continued only for a while as the production flow rate decrease until it is more profitable to shut down another oil well instead of further choking the valves. In Table III, for $q_{\text {tot }}^{\max }=5900 \mathrm{Sm}^{3} /$ day, well 2 is shut down in addition to well 3 . At the same time, the speeds of the active well 1 and well 4 are increased to $49.3224 \mathrm{~Hz}$ and $51.3949 \mathrm{~Hz}$ respectively from $45 \mathrm{~Hz}$ and their choke valves are fully opened. If the production demand is lowered below $5900 \mathrm{Sm}^{3} /$ day, the production flow rates can once again be controlled by controlling the speed of the pumps with $u^{i}=100 y^{i} \%$ until a capacity of $5170.2 \mathrm{Sm}^{3} /$ day when all the active pumps are at back to their lowest allowed speed of $45 \mathrm{~Hz}$. Fulfillment of even more lower production demand is controlled again by choking the valves of the active oil wells with $f_{r}^{i}=45 y^{i} \mathrm{~Hz}$ until it is profitable to shut down additional oil well.

This continues until the oil field is running with only a single oil well. From Table III and from Table II, when only well 4 is running at its lowest operating speed of $45 \mathrm{~Hz}$ with its valve at $100 \%$, the amount of fluid transported to the separator is $2817 \mathrm{Sm}^{3} /$ day. However, the valve of well 4 can be further choked if the total production flow rate is further decreased. With $f_{r}^{4}=45 \mathrm{~Hz}$, the valve of well 4 can be choked to up to $54 \%$ for fulfilling the production flow rate up to $1632.7 \mathrm{Sm}^{3} /$ day. It cannot be choked below $54 \%$ because the operating point will otherwise lie outside the operating window of the pump.

Thus from this section, it can be understood that the operation of the ESP lifted oil field can be improved by choking the production valves of the wells of the field. In fact the well operation follows a specific pattern as follows: "Control the production demand by using the speed of the pumps and keep the choke valves fully opened until all the active wells are operating at their lowest allowed speed of 45 $\mathrm{Hz}$. As production demand decreases, choke the production valves of the active wells and keep their pump speeds constant at $45 \mathrm{~Hz}$. Follow this until it is more profitable to shut down additional wells. Again control the lower production demand by using the speed of the pumps of the remaining active wells and keep their valves fully opened. Follow this, until remaining active wells are all operating at $45 \mathrm{~Hz}$ after which valve choking can once again be performed. Repeat this process, until the field is running with only a single oil well".

With the improved well operation through valve choking, the well selection also follows a specific pattern as explained in Section III-B. The selection of the oil wells are based on their water cut values. The oil well with highest water cut is shut down first, followed by wells with lower water cuts. Similarly, the distribution of the speed of the pumps among the selected oil wells is also based on the water cut values. The oil well with lowest water cut value will be assigned the highest speed followed by other wells with higher water cut 
values.

\section{SimUlation EXAMPLE}

The operation of the ESP lifted oil field can be optimally controlled with a two level control hierarchy. The MINLP optimizer can function as a supervisory controller which provides set points to the lower level local controllers. The speed of the ESP of each oil well can be controlled using a PI controller. The electrical frequency of the three phase supply can be manipulated to control the speed of the pump. Similarly the optimal fluid flow rate through each well can be controlled by manipulating the production choke valve openings of the well using a PI controller as shown in Fig. 4. The PI controllers are tuned by trial and error to give good performance. The production choke valves cannot be opened/closed by more than $1 \%$ per second and the speed of the ESPs cannot be changed by more than $1 \mathrm{~Hz}$ per second if the pumps are working inside the operating window. However, for shutting down a well, specific actions are applied as follows [9]:

- The speed of the pump is varied at the rate of $1 \mathrm{~Hz}$ per second until it reaches $30 \mathrm{~Hz}$.

- From $30 \mathrm{~Hz}$ to $0 \mathrm{~Hz}$, the rate of change of the pump speed is $5 \mathrm{~Hz}$ per second.

- The production choke valve is simultaneously closed at the rate of $1 \%$ closing per second.

The simulation is started with a production flow rate demand of $9000 \mathrm{Sm}^{3} /$ day. For this flow rate, all the wells of the field are used. The optimal speed of the pumps for well 1 to well 4 are $50.1264 \mathrm{~Hz}, 46.7368 \mathrm{~Hz}, 45.1519 \mathrm{~Hz}$ and $51.7643 \mathrm{~Hz}$ respectively as shown in Fig. 5(a). The optimal fluid flow rates from well 1 to well 4 are 1561.4, 1550.9, 1069.2 and $1729.8 \mathrm{Sm}^{3} /$ day respectively (Fig. 5(d)) and hence the corresponding choke valve openings of each oil well is $100 \%$ as shown in Fig. 5(b). The total power consumed by the pumps is $829.911 \mathrm{HP}$ as shown in Fig. 5(c). The total fluid flowing through the both the transportation is equal to the production flow rate demand of $9000 \mathrm{Sm}^{3} /$ day (Fig. 5(e)). All the wells are operating safely inside their operating window as shown in Fig. 5(f).

At the simulation time of 50 seconds, the production flow rate demand is decreased to $7100 \mathrm{Sm}^{3} /$ day. The MINLP problem is again solved for this new production flow rate and a set of new optimal solutions are obtained. These are then provided as the set points to the local PI controllers. After simulation time of 50 seconds for fulfilling the decreased production flow rate, well 3 is shut down. The choke valve and the pump speed of well 3 are taken towards zero by the controllers as seen in Fig. 5(b) and Fig. 5(a) respectively. The production choke valve of well 1 is choked to $88.9581 \%$ and the valve openings of well 2 and well 4 are still $100 \%$ at their steady states. The speeds of the pumps of the active wells (well 1, well 2 and well 4) are running at their minimum allowed speed of $45 \mathrm{~Hz}$ each. The total power consumed by the active pumps is 497.9386 HP (Fig. 5(c)). The optimal fluid flow rates through the active oil wells are 1412.6, 1591.3 and $1536.5 \mathrm{Sm}^{3} /$ day respectively as shown in Fig. $5(\mathrm{~d})$. The head produced by the pump of well 3 is decreased to zero and all the active wells are running safely inside their operating window as can be seen from Fig. 5(f). The production demand of $7100 \mathrm{Sm}^{3} /$ day is fulfilled as shown in Fig. 5(e). At the steady states, the simulation results are exactly the same as listed in Table III for the production flow rate of $9000 \mathrm{Sm}^{3} /$ day and $7100 \mathrm{Sm}^{3} /$ day for the simulation time before and after 50 seconds respectively.

\section{CONCLUSION}

Selection and the identification of the number of oil wells in an ESP lifted oil field to be used for a specified total production flow rate is formulated as a MINLP problem. The problem is solved using the Branch and Bound method implemented in BONMIN solver for calculating the optimal pump speed and the production choke valve openings of the wells. The wells to be operated are selected on the basis of their water cut values. Similarly, the distribution of the speed of the pumps of the selected oil wells are also based on the water cut values of the oil wells. The use of production choke valves for controlling the fluid flow rate from the wells improves the operation of the oil field. By choking the production choke valve for regulating the total flow rate, the power consumed by the pumps can be significantly reduced.

\section{REFERENCES}

[1] G. W. Rosenwald and D. W. Green, "A method for determining the optimum location of wells in a reservoir using mixed-integer programming," Society of Petroleum Engineers journal, vol. 14, no. 1, pp. 44-54, 1974.

[2] J. E. Murray and T. F. Edgar, "Optimal scheduling of production and compression in gas fields," Journal of Petroleum Technology, vol. 30, pp. 109-116, Jan 1978.

[3] T. Westerlund, F. Pettersson, and I. E. Grossmann, "Optimization of pump configurations as a MINLP problem," Computers and Chemical Engineering, vol. 18, no. 9, pp. 845-858, September 1994.

[4] F. Pettersson and T. Westerlund, "Global optimization of pump configurations using binary separable programming," Computers \& Chemical Engineering, vol. 21, no. 5, pp. 521-529, 1997.

[5] Z. Yang and H. Børsting, "Energy efficient control of a boosting system with multiple variable speed pumps in parallel," in Proc. $49^{\text {th }}$ IEEE Conference on Decision and Control, Hilton Atlanta Hotel, Atlanta, GA, USA, December 15-17 2010, pp. 2198-2203.

[6] D. A. Savic, G. A. Walters, and M. Schwab, "Multiobjective genetic algorithms for pump scheduling in water supply," Lecture notes in Computer Science, vol. 1305, pp. 227-235, 1997.

[7] J. Y. Wang, T. P. Chang, and J. S. Chen, "An enhanced genetic algorithm for bi-objective pump scheduling in water supply," Expert Systems with Applications, vol. 36, no. 7, pp. 10 249-10 258, 2009.

[8] G. AlQahtani, A. Alzahabi, E. Kozyreff, I. Farias, and M. Soliman, "A comparison between evolutionary metaheuristics and mathematical optimization to solve the wells placement problem," Advances in Chemical Engineering and Science, vol. 3, pp. 30-36, 2013.

[9] R. Sharma and B. Glemmestad, "Modeling and simulation of an electric submersible pump lifted oil field," International Journal of Petroleum Science and Technology, vol. 8, no. 1, pp. 39-68, 2014.

[10] R. Sharma and B. Glemmestad, "Optimal control strategies with nonlinear optimization for an electric submersible pump lifted oil field," Modeling, Identification and Control, vol. 34, no. 2, pp. 55-67, 2013.

[11] R. Sharma and B. Glemmestad, "Nonlinear optimization and control of an electric submersible pump lifted oil field," in Proc. the 5th International Conference on Modeling, Identification and Control, Cairo, Egypt, Aug. 31 - Sept. 2 2013, pp. 26-31.

[12] P. C. Krause, Analysis of Electric Machinery, McGraw-Hill Book Company, 1986.

[13] R. Sharma and B. Glemmestad, "Nonlinear model predictive control for optimal operation of electric submersible pump lifted oil field," in Proc. the 33rd IASTED International Conference on Modeling, 
Identification and Control, Innsbruck, Austria, Feb. 17-19 2014, pp. 229-236.

[14] H. Brinkman, "The viscosity of concentrated suspensions and solutions," Journal of Chemical Physics, vol. 20, no. 4, pp. 571-584, 1952.

[15] Hydraulic Institute. (2012) ANSI-HI Pump Standards. [Online]. Available: www.pumps.org.

[16] I. Karassik and T. M. Guire, Centrifugal Pumps, 2nd ed. New York, USA: Chapman and Hall, 1998.

[17] G. Takacs, Electric Submersible Pump Manual: Design, Operation and Maintenance, Jordan Hill, Oxford, UK: Gulf Professional Publishing, 2009.

[18] ANSI/ISA S75.01, Flow Equations for Sizing Control Valves, Standards and Recommended Practices for Instrumentation and Control, 10th ed., 1989, vol. 2.

[19] K. E. Brown and H. D. Beggs, The Technology of Artificial Lift Methods, Inflow Performance, Multiphase Flow in Pipes, The flowing Well, Tulsa, Oklahoma, ISBN: 0-87814-031-X: PennWell Publishing Company, 1977, vol. 1.

[20] T. K. Serghide, "Estimate friction factor accurately," Chemical Engineering, vol. 91, no. 5, pp. 63-64, 1984.

[21] T. F. Edgar, D. M. Himmelblau, and L. S. Lasdon, Optimization of chemical processes, 2nd ed. New York, USA: McGraw-Hill Book Company, 2001.

[22] COIN-OR. (2013, Sep.) Computational infrastructure for operations research - open source for the operations research community. [Online] Available: http://www.coin-or.org

[23] J. Currie and D. I. Wilson, OPTI: Lowering the Barrier between Open Source Optimizers and the Industrial MATLAB User. [Online] Available: http: //www.i2c2.aut.ac.nz/ Wiki/OPTI/index.php

[24] P. Bonami and J. Lee. (May 2013). BONMIN Users Manual. [Online]. Available: http://www. projects.coin-or.org/Bonmin

[25] G. L. Nemhauser and L. A. Wolsey, Integer and Combinatorial Optimization, New York: John Wiley, 1988.

[26] P. Bonami, M. Kilinc, and J. Linderoth, "Algorithms and softwares for convex mixed integer nonlinear programs," Mixed Integer Nonlinear
Programming, The IMA Volumes in Mathematics and its Applications, 2012, vol. 154, pp. 1-40.

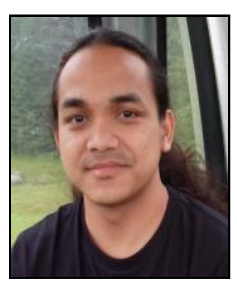

Roshan Sharma was born in 1982 in Nepal. He received his bachelor in engineering from Tribhuvan University in 2007. After about 2 years of academic experience working as an assistant lecturer, he received M.Sc in systems and control engineering from Telemark University College, Norway. Currently he is a PhD student at Telemark University College. His main areas of research are in the field of process modeling, simulation, control and optimization. At present, he is working on the design and implementation of optimal control structures for artificially lifted oil wells. He is focused on optimal control of Gas lifted and ESP lifted oil fields.

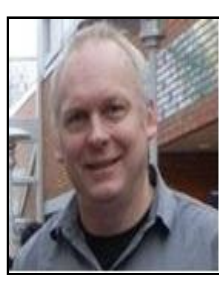

Bjørn Glemmestad was born in Norway. $\mathrm{He}$ received his B.Sc. from Telemark University College in 1986. After six years industrial experience he received a M.Sc. in process automation at Telemark University College in 1994 and his $\mathrm{PhD}$ within process technology from Norwegian University of Science and Technology in 1997. Since then Glemmestad has worked several years on the petrochemical industry being involved in energy and environmental issues in Norsk Hydro AS, but the main focus has been on systems for advanced process control (APC) and process optimization at the Borealis Petrochemical Group. He has been involved in developing proprietary APC technology and implementing this at petrochemical plants in several countries, and he was a manager for the APC Department in the Borealis Group for four years. In 2009 he started as a professor in industrial optimization at Telemark University College and was the head of Department for Process, Energy and Environmental Technology until 2013. Currently, he works at Yara International AS, Porsgrunn, Norway. 